\begin{tabular}{|c|c|}
\hline Title & Characterization of the Solid State Properties of A nodic Oxides on Magnetron Sputtered Ta, Nb and Ta Nb A lloys \\
\hline Author(s) & Di Franco, F.; Zampardi, G.; Santamaria, M.; Di Quarto, F.; Habazaki, H. \\
\hline Citation & $\begin{array}{l}\text { Journal of the Electrochemical Society, 159(1), C33-C39 } \\
\text { https://doi.org/10.1149/2.031201jes }\end{array}$ \\
\hline Issue Date & 2012 \\
\hline Doc URL & http://hdl.handle.net/2115/48149 \\
\hline Rights & $\begin{array}{l}\text { (c) The Electrochemical Society, Inc. 2011. All rights reserved. Except as provided under U.S. copyright law, this work } \\
\text { may not be reproduced, resold, distributed, or modified without the express permission of The Electrochemical Society } \\
\text { (ECS). The archival version of this work was published in J. Electrochem. Soc., V olume 159, Issue 1, pp. C } 33 \text { C } 39 \\
\text { (2012) }\end{array}$ \\
\hline Tyре & article \\
\hline File Information & JES159-1_C33-C39.pdf \\
\hline
\end{tabular}

Instructions for use 


\title{
Characterization of the Solid State Properties of Anodic Oxides on Magnetron Sputtered Ta, Nb and Ta-Nb Alloys
}

\author{
F. Di Franco, ${ }^{a}$ G. Zampardi, ${ }^{a}$ M. Santamaria, ${ }^{a, *, z}$ F. Di Quarto, ${ }^{a}$ and H. Habazaki ${ }^{b, *}$ \\ ${ }^{a}$ Electrochemical Materials Science Laboratory, Facoltà di Ingegneria, Viale delle Scienze, Università di Palermo, \\ 90128 Palermo, Italy \\ ${ }^{b}$ Graduate School of Engineering, Hokkaido University, Sapporo 060-8628, Japan
}

Tantalum oxide, niobium oxide and $\mathrm{Ta}-\mathrm{Nb}$ containing mixed oxides were grown by anodizing sputter-deposited $\mathrm{Ta}, \mathrm{Nb}$ and $\mathrm{Ta}-\mathrm{Nb}$ alloys of different compositions. A photoelectrochemical investigation was performed in order to estimate the band gap and the flat band potential of the oxides as a function of their composition. The band gap of the investigated Ta-Nb containing mixed oxides changed monotonically between those estimated for $\mathrm{Ta}_{2} \mathrm{O}_{5}(4.1 \mathrm{eV})$ and $\mathrm{Nb}_{2} \mathrm{O}_{5}(3.4 \mathrm{eV})$ and in agreement with a proposed correlation between the Band gap of an oxide and the difference of electronegativity of the oxide constituents. From the differential capacitance curves recorded in a wide range of electrode potential and for several frequencies of the alternative signal, the dielectric constant of the investigated oxides were estimated.

C) 2011 The Electrochemical Society. [DOI: 10.1149/2.031201jes] All rights reserved.

Manuscript submitted August 11, 2011; revised manuscript received October 3, 2011. Published December 8, 2011. This was Paper 1905 presented at the Boston, Massachusetts, Meeting of the Society, October 9-14, 2011.

Microelectronics is very important for almost all kinds of technology evolutions in the past four decades. In this area, the dielectrics science occupies a prominent place in providing the dominant technology in integrated capacitors or gate insulators. In the last years the main challenge has been to scale down the insulating oxide thickness keeping low values of the leakage current. This task has been partially achieved for metal-oxide-semiconductor field effect transistor thanks to the use of hafnium based dielectrics, while less has been done for dynamic random access memory and metal-insulator-metal capacitors (DRAM MIMCAP). To the last generation DRAM, very low (from 0.5 to $0.35 \mathrm{~nm}$ ) equivalent thickness is required with the constraint to maintain a very low leakage current. This implies the use of material having high dielectric constant $(\sim 50)$ and high band gap $(>4 \mathrm{eV})$, which can be obtained by post formation thermal treatment and tuning of the oxide composition. Owing to their high value of dielectric constant, $\mathrm{Ta}_{2} \mathrm{O}_{5}$ and $\mathrm{Nb}_{2} \mathrm{O}_{5}$ are quite attractive oxides for the development of the next generation of DRAM. Tantalum oxide is a wide band gap $(\sim 4 \mathrm{eV})$ material with a high dielectric constant $(\varepsilon=27-30)$ if properly crystallized $\left(\mathrm{T}>750^{\circ} \mathrm{C}\right)$. Niobium oxide has a higher dielectric constant $(\varepsilon=53)$ with respect to $\mathrm{Ta}_{2} \mathrm{O}_{5}$ but a lower band gap $(\sim 3.3 \mathrm{eV})$. In recent papers, ${ }^{1-3}$ it has been shown that the addition of small amount of $\mathrm{Nb}$ in tantalum based oxide decreases the crystallization temperature with small effect on the band gap value of the material. Thus, $\left(\mathrm{Nb}_{(1-\mathrm{x})} \mathrm{Ta}_{\mathrm{x}}\right)_{2} \mathrm{O}_{5}$ have been introduced in the International Technology Roadmap for Semiconductors (ITRS).

Tantalum-niobium mixed oxides for microelectronic components are usually prepared by high vacuum techniques (physical and chemical vapour depositions, atomic layer deposition). ${ }^{4-7}$ In this work we propose to prepare these oxides by anodizing in suitable solutions sputter-deposited Nb-Ta alloys. This electrochemical room temperature process allows to grow oxides of controlled thickness and composition, even if a detailed investigation on the dielectric properties of these anodic films is necessary before considering their effective use in microelectronics. Once grown, the oxides were characterized by Photocurrent Spectroscopy (PCS) in order to study their solid state properties (band gap, $\mathrm{E}_{\mathrm{g}}$, flat band potential, $\mathrm{U}_{\mathrm{FB}}$ ) a function of their composition. Impedance measurements were performed to get information of their electronic properties and dielectric constant.

\section{Experimental}

$\mathrm{Ta}, \mathrm{Nb}$ and $\mathrm{Ta}-\mathrm{Nb}$ alloy films were prepared by dc magnetron sputtering. Targets consisted of a $99.9 \%$ niobium disk, of $100 \mathrm{~mm}$

\footnotetext{
* Electrochemical Society Active Member.

${ }^{\mathrm{z}}$ E-mail: monica.santamaria@unipa.it
}

diameter, with an appropriate number of $99.9 \%$ tantalum disks, of $20 \mathrm{~mm}$ diameter, located symmetrically on the erosion region for preparation of the alloys. Substrates were glass plates. Thickness of metallic layer was $300 \mathrm{~nm}$. In order to obtain alloy films of uniform thickness and composition, the substrate holders were rotated around the central axis of the chamber, as well as about their own axes, during sputter deposition. As reported in ref. 8, tantalum and $\mathrm{Ta}-\mathrm{Nb}$ alloys containing up to 22 at.\% niobium comprised the $\beta$ Ta phase, with a tetragonal structure. Further increase in the niobium content resulted in the formation of a body centered cubic phase. All the alloys appear to be mainly single-phase solid solutions, whose compositions were determined by Rutherford backscattering spectroscopy. ${ }^{8}$

Anodizing was undertaken in $0.1 \mathrm{M}$ sodium hydroxide $(\mathrm{NaOH})$ at $298 \mathrm{~K}$ potentiodynamically at $10 \mathrm{mV} \mathrm{s}^{-1}$. Sodium hydroxide was chosen to avoid incorporation of species from the anodizing bath that can influence the solid state properties of the anodic films.

A saturated silver/silver chloride electrode $(0 \mathrm{~V}$ vs $\mathrm{Ag} / \mathrm{AgCl}$ $=0.197 \mathrm{~V}$ vs SHE) was employed as reference electrode for all the electrochemical and photoelectrochemical experiments.

The experimental set-up employed for the photoelectrochemical investigations is described elsewhere: ${ }^{9}$ it consists of a $450 \mathrm{~W}$ UVVIS xenon lamp coupled with a monochromator (Kratos), which allows monochromatic irradiation of the specimen surface through the electrochemical cell quartz windows. A two-phase lock-in amplifier (EG\&G) was used in connection with a mechanical chopper (frequency: $13 \mathrm{~Hz}$ ) in order to separate the photocurrent from the total current circulating in the cell due to the potentiostatic control. Photocurrent spectra reported below are corrected for the relative photon flux of the light source at each wavelength, so that the photocurrent yield in arbitrary current units is represented in the $\mathrm{Y}$ axis. All the experiments were performed in air at room temperature.

Differential capacitance curves were recorded in $0.5 \mathrm{M} \mathrm{H}_{2} \mathrm{SO}_{4}$ solution by using a Parstat 2263 (PAR), connected to a computer for the data acquisition. For all the experiments, a Pt net having a very high surface area was used as counter electrode and a silver/silver chloride electrode was employed as reference electrode.

\section{Results and Discussion}

Anodic film growth.- Anodic films were grown to $5 \mathrm{~V}$ at $10 \mathrm{mV} \mathrm{s}^{-1}$ on all investigated materials. In Fig. 1 we report the growth curves relating to the anodizing of $\mathrm{Ta}, \mathrm{Nb}$ and $\mathrm{Ta}-66 \mathrm{at} . \% \mathrm{Nb}$. As typical of valve metals, after an abrupt increase, the current density reaches an almost constant value, which is a function of the metallic 


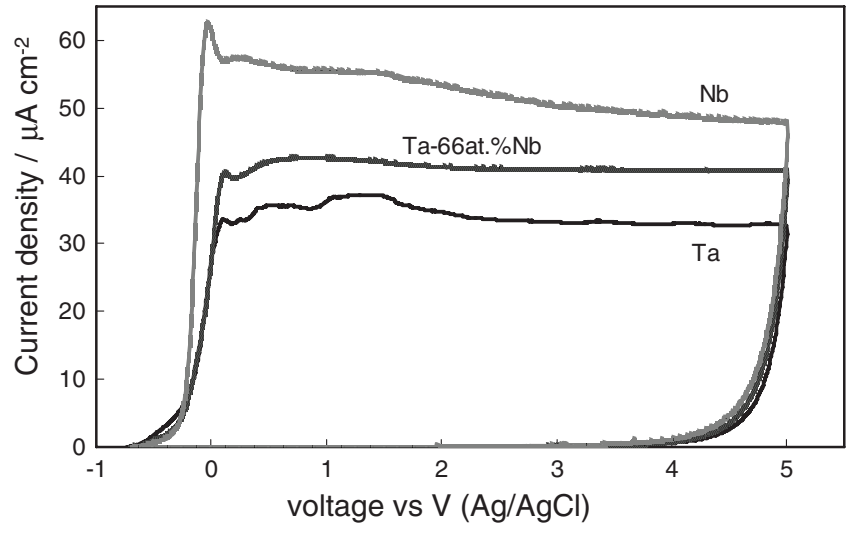

Figure 1. Current density vs potential curves recorded during the potentiodynamic anodizing of $\mathrm{Ta}, \mathrm{Nb}$ and $\mathrm{Ta}-66 \mathrm{at} . \% \mathrm{Nb}$ at $10 \mathrm{mV} \mathrm{s}^{-1}$ in $0.1 \mathrm{M} \mathrm{NaOH}$.

substrate composition. The current density is sustained by the oxidation of metals, according to the following half cell reaction:

$$
2 \mathrm{Me}+5 \mathrm{H}_{2} \mathrm{O} \rightarrow \mathrm{Me}_{2} \mathrm{O}_{5}+10 \mathrm{H}++10 \mathrm{e}-
$$

where $\mathrm{Me}$ is $\mathrm{Ta}$ or $\mathrm{Nb}$ or one of the investigated alloys. According to Faraday's law in the case of high field growth of anodic films, it is possible to relate the electric field strength, $E_{d}$, to the growth rate, $\mathrm{dV} / \mathrm{dt}$, according to eq.:

$$
\frac{\mathrm{dV}}{\mathrm{dt}}=\eta \frac{\mathrm{iE} \mathrm{d}_{\mathrm{d}} \mathrm{M}}{\mathrm{zF} \rho}
$$

in which $i$ is the measured current density, $M$ is the molecular weight of the growing oxide, $\mathrm{z}$ the number of electrons circulating per mole of formed oxide (i.e. 10), F the Faraday constant, $\rho$ the film density and $\eta$ the growth efficiency. $\eta$ is defined as:

$$
\eta=\frac{i_{\text {form }}}{i_{\text {tot }}}=\frac{i_{\text {form }}}{i_{\text {form }}+i_{\text {diss }}+i_{\text {el }}}
$$

where $i_{\text {form }}$ is the current density effectively employed for the film formation, $i_{\text {diss }}$ is the current density fraction due to dissolution phenomena, expected to be negligible for all the investigated samples according to the Pourbaix diagrams relating to $\mathrm{Ta}$ and $\mathrm{Nb},{ }^{10}$ and $\mathrm{i}_{\mathrm{el}}$ is the electronic current which is negligible due the blocking character of the oxides, as confirmed by the very low current circulating during the reverse scan.

In Table I we report the electric field strengths and the anodizing ratios, $\tilde{A}$, (i.e. the reciprocal of $E_{d}$ ) calculated by eq. 1 from the current density measured during the forward scan. We have assumed for the mixed oxides a density and a molecular weight obtained by averaging according to the alloy composition the corresponding data pertaining to pure $\mathrm{Nb}_{2} \mathrm{O}_{5}$ and $\mathrm{Ta}_{2} \mathrm{O}_{5}$. Rutherford back scattering analysis

\begin{tabular}{|c|c|c|c|}
\hline Alloy & $\mathrm{E}_{\mathrm{d}} / \mathrm{MV} \mathrm{cm}^{-1}$ & $\tilde{\mathrm{A}} / \AA ̊ \mathrm{~V}^{-1}$ & Oxide thickness/Å \\
\hline $\mathrm{Ta}$ & 4.8 & 21 & 114 \\
\hline Ta-10at. $\% \mathrm{Nb}$ & 4.30 & 23 & 121 \\
\hline Ta-19at.\% Nb & 4.2 & 24 & 130 \\
\hline Ta-39at.\% $\mathrm{Nb}$ & 4.0 & 25 & 134 \\
\hline Ta-66at.\% Nb & 3.8 & 26 & 140 \\
\hline Ta-85at. $\% \mathrm{Nb}$ & 3.4 & 29. & 163 \\
\hline $\mathrm{Nb}$ & 3.2 & 31 & 185 \\
\hline
\end{tabular}

Table I. Kinetic parameters estimated for the anodizing of $\mathrm{Ta}, \mathrm{Nb}$ and Ta-Nb alloys.

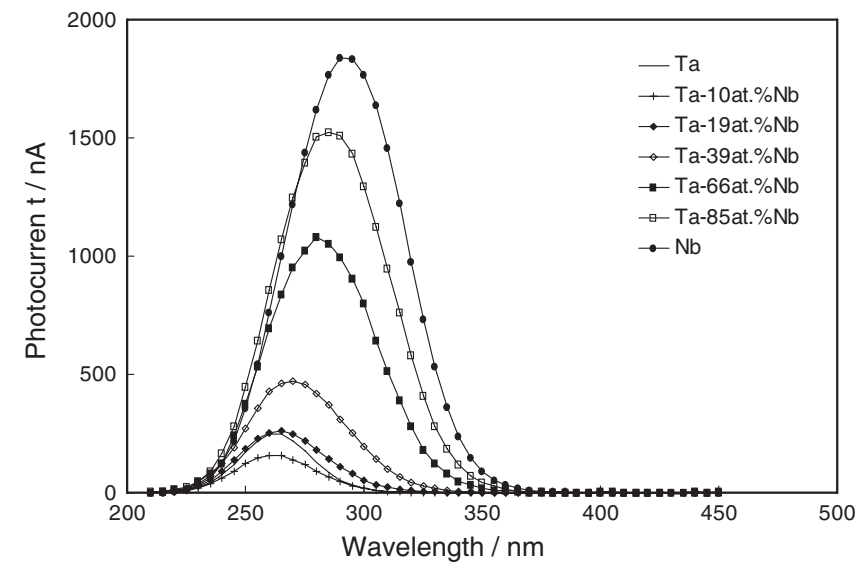

Figure 2. Raw photocurrent spectra relating to anodic films grown on all investigated alloys to $5 \mathrm{~V}$, recorded by polarizing the electrodes at $2 \mathrm{~V}$ in $0.5 \mathrm{M} \mathrm{H}_{2} \mathrm{SO}_{4}$.

revealed that the oxide composition is almost coincident with the base alloy composition ${ }^{8}$ due to comparable migration rate of $\mathrm{Nb}^{5+}$ and $\mathrm{Ta}^{5+}$ during the anodizing process. ${ }^{8}$ It is interesting to mention that the $E_{d}$ (and thus $\tilde{A}$ ) values estimated for mixed oxides changes monotonically as a function of the base alloy composition. In Table I we also report the oxides' thickness for all the investigated anodized alloys, estimated from the measured total circulated charge during the anodizing process, according to the integrated version of eq. 1 . The films become thicker with increasing the $\mathrm{Nb}$ content and their value compares well with those reported in ref. 8, estimated for thicker anodic films by the direct observation of the transmission electron micrographs of their ultramicrotomed cross section, taking into account the different formation voltage and the higher formation rate. ${ }^{8}$

Photoelectrochemical study. - In Fig. 2 we report the photocurrent spectra (photocurrent vs irradiating wavelength curves at constant potential) recorded by polarizing the anodic films grown on all the investigated alloys at $2 \mathrm{~V}$ in $0.5 \mathrm{M} \mathrm{H}_{2} \mathrm{SO}_{4}$. By recording the total current circulating in the dark and under irradiation, we verified that the photocurrent was anodic at all the investigated wavelengths, as shown in Fig. 3 for anodic films grown on Ta-66at.\% Nb alloys. For photon energy in the vicinity of the band gap the following equation holds:

$$
\left(\mathrm{I}_{\mathrm{ph}} \mathrm{h} v\right)^{\mathrm{n}} \propto\left(\mathrm{h} v-E_{g}^{o p t}\right)
$$

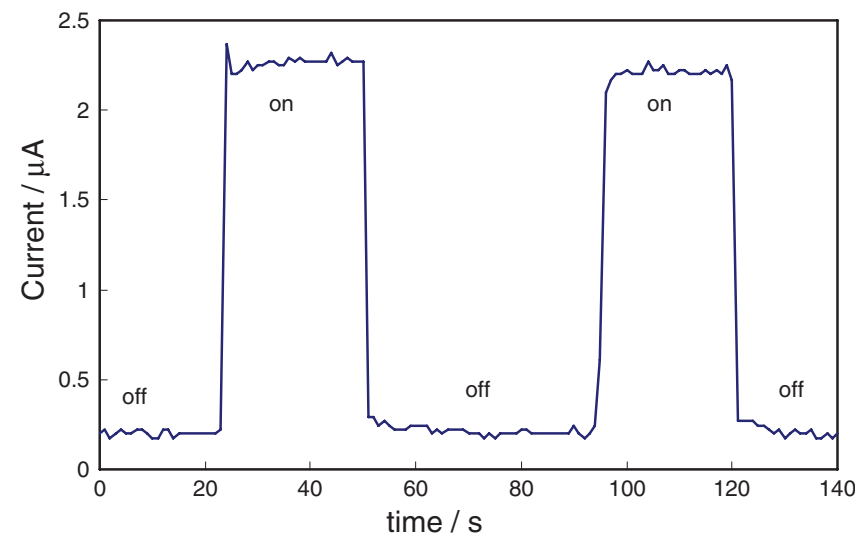

Figure 3. Total current circulating in the dark (off) and under irradiation (on) for anodic films grown on $\mathrm{Ta}-66 \mathrm{at} . \% \mathrm{Nb}$, recorded by polarizing the electrode at $\mathrm{U}_{\mathrm{E}}=2 \mathrm{~V}$ and $\lambda=270 \mathrm{~nm}$ in $0.5 \mathrm{M} \mathrm{H}_{2} \mathrm{SO}_{4}$. 


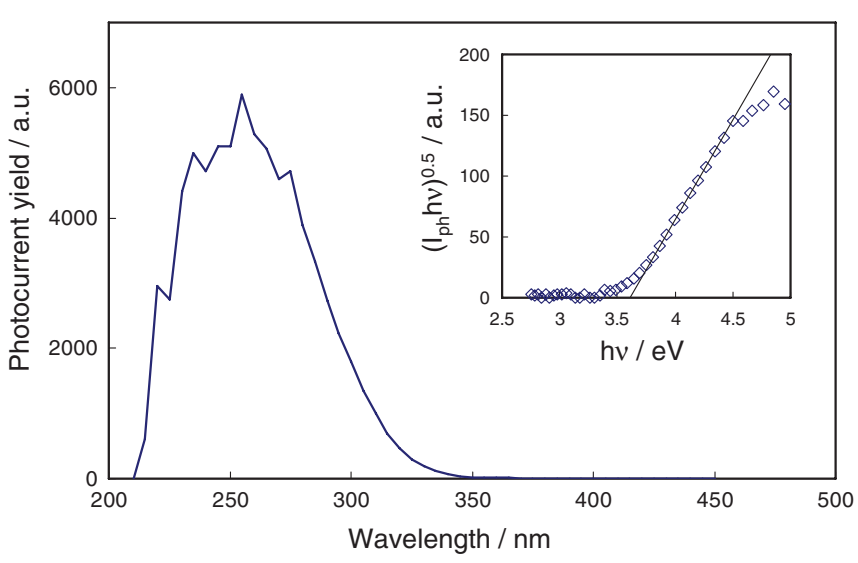

Figure 4. Photocurrent spectrum relating to anodic film grown on Ta66 at. $\% \mathrm{Nb}$ to $5 \mathrm{~V}$, recorded by polarizing the electrode at $2 \mathrm{~V}$ in $0.5 \mathrm{M} \mathrm{H}_{2} \mathrm{SO}_{4}$. Inset: band gap estimate by assuming non direct optical transitions.

where $\mathrm{I}_{\mathrm{ph}}$ is the photocurrent yield, assumed proportional to the light absorption coefficient, hv is the photon energy, $E_{g}^{o p t}$ the optical band gap and the exponent $\mathrm{n}$ is 0.5 for indirect (non direct for amorphous materials) optical transitions. ${ }^{11}$ As shown in Fig. 4 for the anodic film grown on Ta-66at. $\% \mathrm{Nb}$, from the photocurrent spectra corrected for the efficiency of the lamp-monochromator system, ${ }^{9}$ according to eq. 3 we can estimate the optical band gap of the investigated oxides by extrapolating to zero the $\left(I_{\mathrm{ph}} \mathrm{h} v\right)^{0.5}$ vs hv plot. In Fig. 5 we report the $E_{g}^{o p t}$ values estimated with the same procedure for all the investigated oxides. These data clearly show that the band gap value monotonically changes between those estimated for the corresponding pure oxides. This finding suggests that it is possible to tailor the band gap of an oxide by properly selecting the composition of the base alloy to be anodized.

Previous work ${ }^{12}$ proposed that the optical band gaps of crystalline oxides, $\mathrm{M}_{\mathrm{x}} \mathrm{O}_{\mathrm{y}}$, are proportional to the square of the electronegativity difference of their constituents, $\left(\chi_{M}-\chi_{0}\right)^{2}$, based on the assumption of a direct relation between the band gap and the single $\mathrm{M}-\mathrm{O}$ bond energy, obtained from the Pauling equation for the single bond energy.

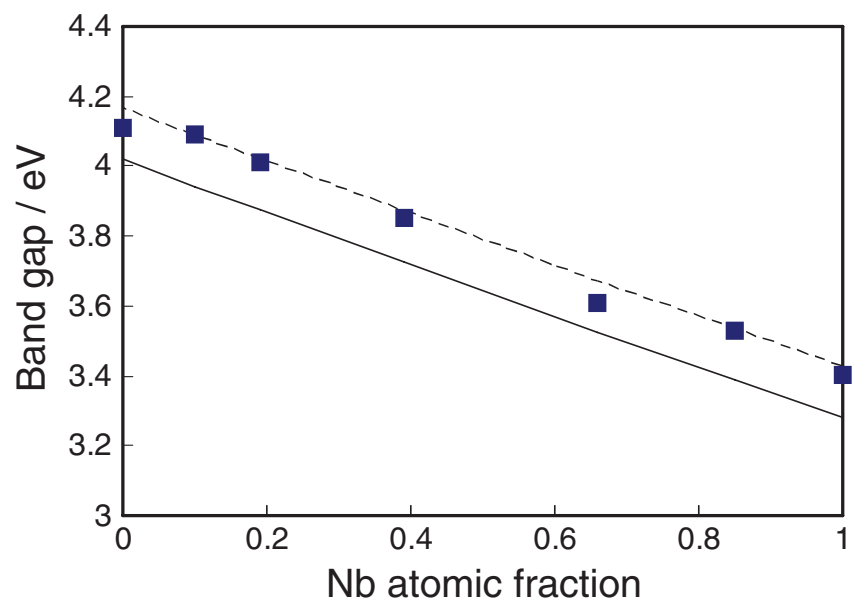

Figure 5. Experimental band gap values for $\mathrm{Ta}$ and $\mathrm{Nb}$ containing mixed oxides as a function of the $\mathrm{Nb}$ atomic fraction, $\mathrm{x}_{\mathrm{Nb}}$. Continuous line represents the theoretical prediction for crystalline oxides according to eqs 4 and 5. Dotted line represents the theoretical prediction for amorphous oxides according to eqs 4 and 5 with $\Delta \mathrm{E}_{\mathrm{am}}=0.15 \mathrm{eV}$.
The following equation has been suggested to apply ${ }^{13,14}$ to amorphous d metal oxides:

$$
\mathrm{E}_{\mathrm{g}}^{\mathrm{opt}}-\Delta \mathrm{E}_{\mathrm{am}}(\mathrm{eV})=1.35\left(\chi_{\mathrm{M}}-\chi_{\mathrm{O}}\right)^{2}-1.49
$$

$\Delta \mathrm{E}_{\mathrm{am}}=0$ for crystalline oxides, when $\mathrm{E}_{\mathrm{g}}^{\mathrm{opt}}=\mathrm{E}_{\mathrm{g}}$, whilst increasing values are expected (up to around $0.5 \mathrm{eV}$ ) if the lattice disorder affects both density of states distribution (DOS) near the valence and conduction band edges. ${ }^{11}$

For d-metal mixed oxides $\mathrm{A}_{\mathrm{a}} \mathrm{B}_{\mathrm{b}} \mathrm{O}_{\mathrm{y}}$, the previous correlation is still valid provided that the average single bond energy is estimated taking into account the contributions of both, $\mathrm{A}$ and $\mathrm{B}$, cations of the oxide trough an average cationic electronegativity parameter, $\chi_{M}$, given by:

$$
\chi_{M}=x_{a} \chi_{A}+x_{b} \chi_{B}
$$

where $\mathrm{A}$ and $\mathrm{B}$ are the metals of the oxide, and $\mathrm{x}_{\mathrm{a}, \mathrm{b}}$ their cationic fractions. In order to use eqs. 4 and 5 to fit the experimental band gap values of the investigated $\mathrm{Ta}-\mathrm{Nb}$ mixed oxides, we assume $\mathrm{x}_{\mathrm{Ta}}$ $=1.50 \pm 0.05$ and $\chi_{\mathrm{Nb}}=1.60 \pm 0.05$, which are in the range of uncertainty accepted by Pauling. ${ }^{15}$ As Fig. 5 shows $E_{g}^{\text {opt }}$ differs from the values calculated by means of eqs. 4 and 5 , of a quantity which is less than $0.15 \mathrm{eV}$ and in the range foreseen by the taking into account the amorphous nature of the investigated layers.

The good agreement between the experimental $\mathrm{E}_{\mathrm{g}}$ values of $\mathrm{Ta}-\mathrm{Nb}$ mixed oxides and those predicted by eq. 4 is a further evidence of the validity of the correlation between the electronegativity of the oxides' constituents and their band gap. This correlation is a powerful tool for the prediction of the band gap of a material starting from the knowledge of its composition. This statement becomes more convincing if we consider the large approximation provided by Density Functional Theory based methods for $\mathrm{E}_{\mathrm{g}}$ estimation. This is the case of the band gap value calculated in ref. 16 in the Low Density Approximation for $\mathrm{TaNbO}_{5}\left(\mathrm{E}_{\mathrm{g}}=1.82 \mathrm{eV}\right)$, that the authors report to be underestimated and that appears really far from the expected value according to the experimental results of Fig. 5.

For a possible technological application, it is very important that the band gap of the mixed oxides are between those calculated for $\mathrm{Ta}_{2} \mathrm{O}_{5}$ and $\mathrm{Nb}_{2} \mathrm{O}_{5}$, if we consider that oxides with the band gaps over 3-4 eV meet the specifications defined by ITRS. However, the band offset with the metal electrode is also a critical factor that may define the leakage current. Therefore, the knowledge of the energetics of the metal/oxide interface is crucial.

Photocurrent vs electrode potential curves under constant irradiating wavelength (photocharacteristics) were recorded for all the investigated oxides, by scanning the polarizing voltage toward the cathodic direction at $10 \mathrm{mV} \mathrm{s}^{-1}$. As typical of n-type semiconducting materials, the photocurrent decreases by decreasing the polarizing voltage, i.e. the electric field strength across the film. Due the very low thickness of the investigated films, the contribution to the measured photocurrent coming from the field free region is negligible. The zero photocurrent potential, $\mathrm{V}_{\text {on }}$, which can be assumed as a rough estimate of the flat band potential, changes sensitively on going from $\mathrm{Nb}_{2} \mathrm{O}_{5}\left(\mathrm{~V}_{\text {on }}\right.$ $=-0.25 \mathrm{~V})$ to $\mathrm{Ta}_{2} \mathrm{O}_{5}\left(\mathrm{~V}_{\text {on }}=-1.0 \mathrm{~V}\right)$.

In Fig. 6 we report the $\mathrm{I}_{\mathrm{ph}}$ vs polarizing voltage curves relating to $5 \mathrm{~V}$ anodic films grown on Ta, Ta-10at. $\% \mathrm{Nb}$ and $\mathrm{Ta}-19 \mathrm{at} . \% \mathrm{Nb}$. It is interesting to stress that the addition of a small amount of $\mathrm{Nb}$ shifts sensitively the zero photocurrent potential toward more anodic values with respect to $\mathrm{Ta}_{2} \mathrm{O}_{5}$. Owing to the amorphous nature of all the investigated anodic films, we expect an influence of the irradiating photon energy as well as of the electric field strength on the photocurrent. The lack of the long range order for the amorphous oxides is responsible of a reduced mobility of the generated photocarriers, which do not cover during their thermalization time a distance long enough to prevent their recombination. Thus, for amorphous oxides it is not possible to assume as unit the efficiency of free carriers generation even for photon energies higher than the band gap of the material (geminate 


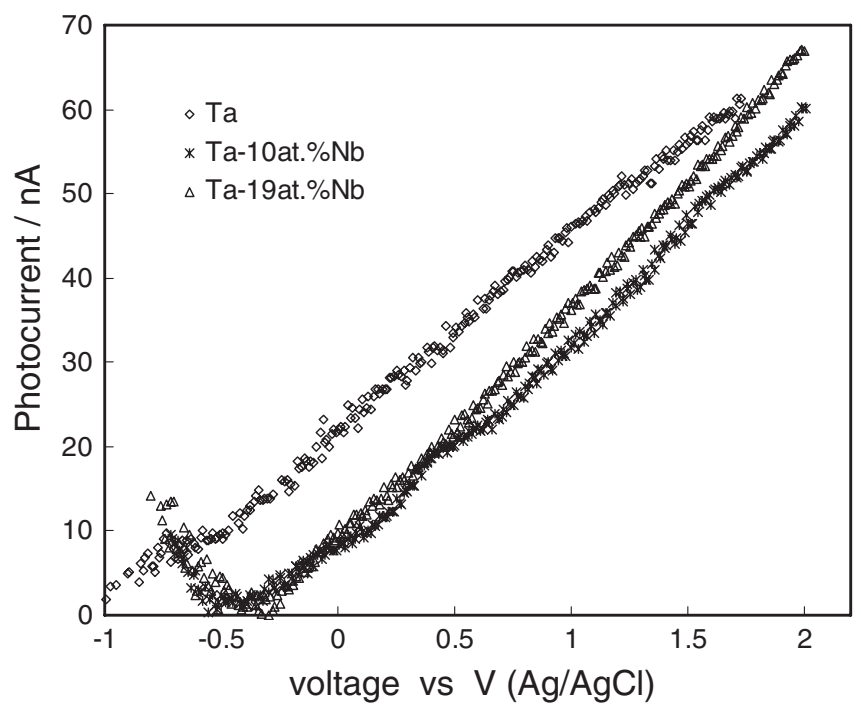

Figure 6. Photocurrent vs potential curves relating to $5 \mathrm{~V}$ anodic films grown on Ta, Ta-10at.\% Nb and Ta-19at.\% Nb. Irradiating wavelength $240 \mathrm{~nm}$, solution: $0.5 \mathrm{M} \mathrm{H}_{2} \mathrm{SO}_{4}$ and potential scan rate $10 \mathrm{mV} \mathrm{s}^{-1}$.

recombination). In order to get information on the mobility of the photocarriers we have fitted the $\mathrm{I}_{\mathrm{ph}}$ vs potential, $\mathrm{U}_{\mathrm{E}}$, curves were fitted according to power law

$$
\left(\mathrm{I}_{\mathrm{ph}}\right)^{\mathrm{n}} \propto\left(\mathrm{U}_{\mathrm{E}}-\mathrm{V}^{*}\right)
$$

The best fitting exponent, $\mathrm{n}$, and the extrapolated zero photocurrent potential, $\mathrm{V}^{*}$, are reported in Table II. A supralinear $(\mathrm{n}<1)$ behavior was evidenced for the oxides grown on Ta rich alloys and, in spite of the narrow energy range we were able to exploit due to the wide band gap of these oxides, it was possible to evidence that $\mathrm{n}$ decreases with increasing the irradiating wavelength, as expected for amorphous films. The estimated $\mathrm{V}^{*}$ confirmed the shift toward anodic potential of the $\mathrm{U}_{\mathrm{FB}}$ for $\mathrm{Nb}$ containing mixed oxides with respect to pure $\mathrm{Ta}_{2} \mathrm{O}_{5}$. The more anodic $\mathrm{U}_{\mathrm{FB}}$ of $\left(\mathrm{Ta}_{0.9} \mathrm{Nb}_{0.1}\right)_{2} \mathrm{O}_{5}$ with respect to pure $\mathrm{Ta}_{2} \mathrm{O}_{5}$ can account for the dependence of photocurrent on oxide composition. A careful inspection of Fig. 2 shows that the measured photocurrent increases with increasing $\mathrm{Nb}$ content with the exception of the anodic film on Ta-10at.\% $\mathrm{Nb}$, for which the $\mathrm{I}_{\mathrm{ph}}$ vs wavelength curve is slightly lower that the corresponding curve for $\mathrm{Ta}_{2} \mathrm{O}_{5}$ in spite of the very close

\begin{tabular}{|c|c|c|c|}
\hline Metallic substrate & Wavelength/nm & $\mathrm{n}$ & $\mathrm{V}^{*}(\mathrm{~V})$ \\
\hline \multirow[t]{3}{*}{$\mathrm{Ta}$} & 240 & 0.975 & -1.00 \\
\hline & 270 & 0.975 & -1.02 \\
\hline & 300 & 0.975 & -0.97 \\
\hline \multirow[t]{2}{*}{$\mathrm{Ta}-10 \mathrm{at} \% \mathrm{Nb}$} & 240 & 0.80 & -0.52 \\
\hline & 270 & 0.65 & -0.45 \\
\hline \multirow[t]{2}{*}{$\mathrm{Ta}-19 \mathrm{at} \% \mathrm{Nb}$} & 240 & 0.90 & -0.39 \\
\hline & 270 & 0.65 & -0.43 \\
\hline \multirow[t]{3}{*}{$\mathrm{Ta}-39 \mathrm{at} \% \mathrm{Nb}$} & 240 & 1.25 & -0.30 \\
\hline & 270 & 0.78 & -0.34 \\
\hline & 300 & 0.73 & -0.32 \\
\hline \multirow{3}{*}{$\mathrm{Ta}-66 \mathrm{at} \% \mathrm{Nb}$} & 240 & 1.15 & -0.26 \\
\hline & 270 & 1.03 & -0.24 \\
\hline & 300 & 0.85 & -0.29 \\
\hline
\end{tabular}

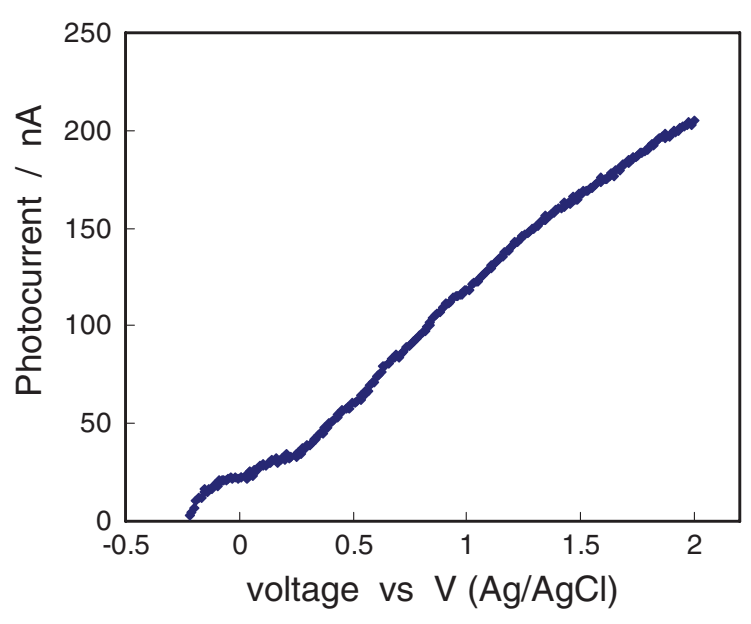

Figure 7. Photocurrent vs potential curve relating to $5 \mathrm{~V}$ anodic films grown on $\mathrm{Nb}$. Irradiating wavelength $340 \mathrm{~nm}$, solution: $0.5 \mathrm{M} \mathrm{H}_{2} \mathrm{SO}_{4}$ and potential scan rate $10 \mathrm{mV} \mathrm{s}^{-1}$.

band gap value. We believe that such a finding can be related to the electric field strength across the mixed oxide which is expected to be lower owing to its more anodic flat band potential.

For higher $\mathrm{Nb}$ content (see Fig. 7), by increasing the irradiating wavelength the dependence of $\mathrm{I}_{\mathrm{ph}}$ on $\mathrm{U}_{\mathrm{E}}$ changes from sublinear to supralinear (see Table II). Such a dependence has been detailed discussed for pure a- $\mathrm{Nb}_{2} \mathrm{O}_{5}$ anodic films and is related to the strong dependence on the electric field of the geminate recombination efficiency. ${ }^{17}$

Differential capacitance study. - In order to get information on the dielectric properties of the investigated oxides, we recorded differential capacitance curves as a function of the a.c. signal frequency as well as of the oxide composition in a wide electrode potential range (from $3 \mathrm{~V}$ to the flat band potential). In Fig. 8 we report the measured series capacitance, $\mathrm{C}_{\mathrm{M}}$, of the $\mathrm{Ta} / \mathrm{Ta}_{2} \mathrm{O}_{5}$ /electrolyte interface recorded in $0.5 \mathrm{M} \mathrm{H}_{2} \mathrm{SO}_{4}$ at three different frequencies. $\mathrm{C}_{\mathrm{M}}$ depends on both the polarizing potential and a.c. frequency, as typical of amorphous semiconductors. However, the measured capacitance becomes almost independent on $\mathrm{U}_{\mathrm{E}}$ when $\mathrm{f}_{\text {a.c. }}=5 \mathrm{kHz}$. By increasing the $\mathrm{Nb}$ content the mixed oxides become more polarisable, as suggested by the differential capacitance recorded at $5 \mathrm{kHz}$ and $100 \mathrm{~Hz}$ for all the investigated

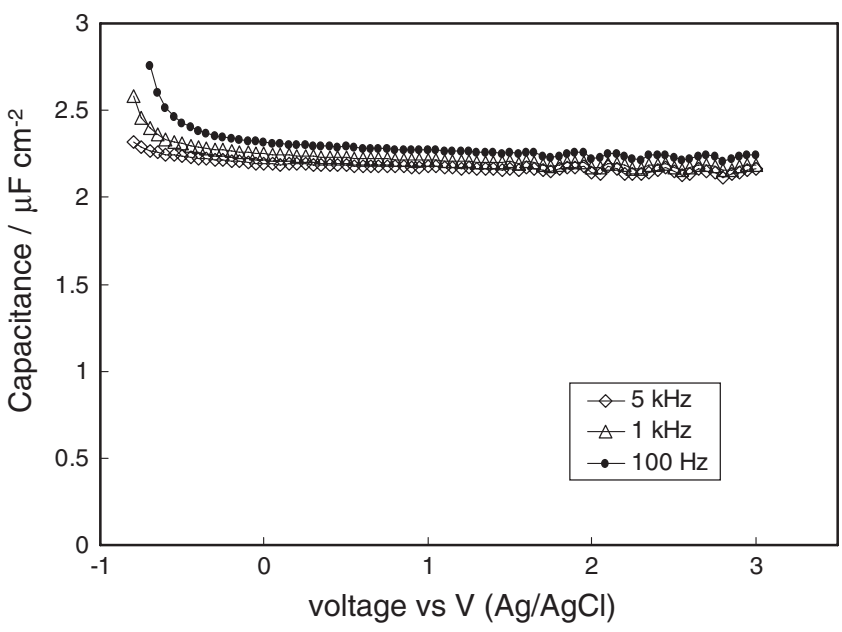

Figure 8. Measured series capacitance, $\mathrm{C}_{\mathrm{M}}$, of the $\mathrm{Ta} / \mathrm{Ta}_{2} \mathrm{O}_{5}$ /electrolyte interface recorded in $0.5 \mathrm{M} \mathrm{H}_{2} \mathrm{SO}_{4}$ at three different frequencies. 

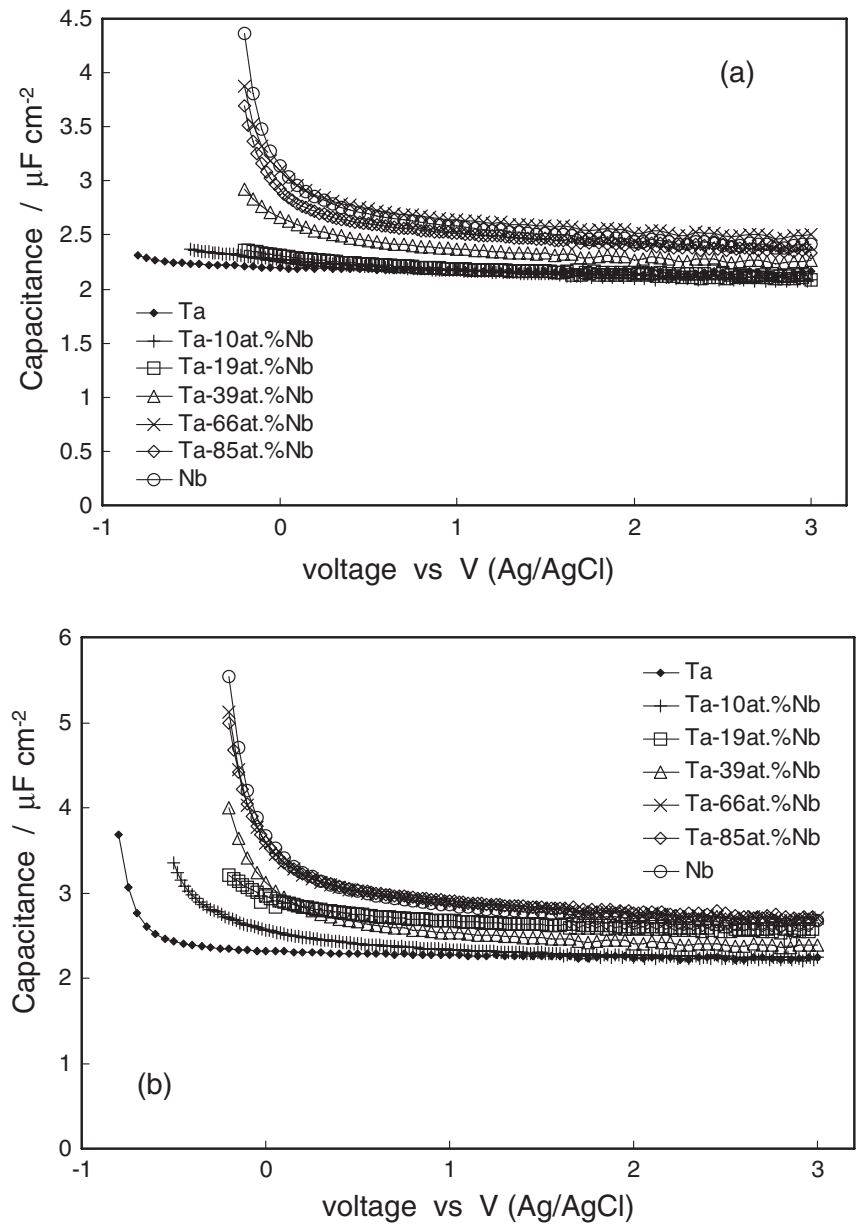

Figure 9. Measured series capacitance, $\mathrm{C}_{\mathrm{M}}$, for all the investigated films recorded in $0.5 \mathrm{M} \mathrm{H}_{2} \mathrm{SO}_{4}$. Frequency of the a.c. signal: a) $5 \mathrm{kHz}$ and b) $100 \mathrm{~Hz}$.

films, reported in Fig. 9. In order to explain the dependence of $\mathrm{C}$ on the polarizing voltage as well as on the a.c., frequency, we have to recall briefly of amorphous semiconductor Schottky barrier, ${ }^{18,19}$ which takes into account the influence on the electronic properties of the short range order of amorphous material. In fact, the main difference between crystalline and amorphous semiconductors is that the space charge region width, $\mathrm{x}_{\mathrm{SC}}$, depends on both the ionized impurities and the localized states within the mobility gap. These electronic states lying into the gap do not follow instantaneously the imposed ac signal, but they need a finite response time, depending on their energy position with respect to the Fermi level, that can be much longer than the period of the ac signal having angular frequency $\omega$. In fact an exponential relaxation time, $\tau$, for the capture/emission of electrons from electronic states $\mathrm{E}$ below $\mathrm{E}_{\mathrm{F}}$ is assumed to hold according to the relationship:

$$
\tau=\tau_{0} \exp \left(\frac{E_{C}-E}{k T}\right)
$$

where, at constant temperature, $\tau_{0}$ is a constant characteristic of each material usually ranging between $10^{-14}-10^{-10} \mathrm{~s}$, and $\mathrm{E}_{\mathrm{C}}$ is the energy level of the conduction band edge. This means that, at constant band bending, the levels which can follow the signal change by changing frequency. On the other hand, at constant ac frequency, by changing the band bending the more deep levels of depleted region lying below a critical level will not change the occupancy with a.c. signal. According to eq. 7 , by decreasing the energy of the localized state in the gap, $\tau$ increases sharply so that deep states (for which $\omega \tau \gg 1$ ) do not respond to the ac signal.

By assuming a full response for states satisfying the condition $\omega \tau$ $\ll 1$ and a null response for states having $\omega \tau \gg 1$, a sharp cutoff energy level, $\mathrm{E}_{\omega}$, separating states responding from those not responding to the signal, can be defined from the condition: $\omega \tau=1$, as:

$$
\mathrm{E}_{\mathrm{C}}-\mathrm{E}_{\omega}=-\mathrm{k}_{\mathrm{B}} \mathrm{T} \ln \left(\omega \tau_{0}\right)
$$

The intersection of $\mathrm{E}_{\omega}$ with the Fermi level of material determines a characteristic point in the barrier, $\mathrm{x}_{\mathrm{C}}$, at which corresponds a band bending $\psi_{\mathrm{C}}$ given by:

$$
|\mathrm{e}| \psi_{\mathrm{C}}=|\mathrm{e}| \psi\left(\mathrm{x}_{\mathrm{C}}\right)=-\mathrm{k}_{\mathrm{B}} \mathrm{T} \ln \left(\omega \tau_{0}\right)-\Delta \mathrm{E}_{\mathrm{F}}
$$

where $\Delta \mathrm{E}_{\mathrm{F}}=\left(\mathrm{E}_{\mathrm{C}}-\mathrm{E}_{\mathrm{F}}\right)_{\text {bulk }} \cdot \mathrm{x}_{\mathrm{C}}$ is a distance in the barrier which changes with changing frequency, $\omega$, and band bending, $\psi_{\mathrm{S}}$. From the theory it comes out that the total capacitance is sum of two series contribution coming from the $\mathrm{x}<\mathrm{x}_{\mathrm{C}}$ and $\mathrm{x}>\mathrm{x}_{\mathrm{C}}$ regions of the a-SC. In the hypothesis of a constant DOS the total capacitance is given by the sum of the two contributions:

$$
\frac{1}{C\left(\psi_{S}, \omega\right)}=\frac{1}{C\left(\psi_{C}, 0\right)}+\frac{x_{C}}{\varepsilon \varepsilon_{0}}
$$

where $C\left(\psi_{C}, 0\right)=\sqrt{\varepsilon \varepsilon_{0} e^{2} N}$ and $x_{C}=\sqrt{\frac{\varepsilon \varepsilon_{0}}{e^{2} N}} \ln \frac{\psi_{S}}{\psi_{C}}, \varepsilon_{0}$ is the vacuum permittivity, $\varepsilon$ is the relative dielectric constant of the oxide and $\mathrm{N}$ is the density of states. The contribution to the measured capacitance deriving from the second term in eq. 10 becomes more significant with decreasing the a.c. signal frequency and by decreasing the band bending. Thus, we expect that the higher is the measured capacitance the lower is $\omega$ (compare Figs. 9a and $9 \mathrm{~b}$ ), and that $\mathrm{C}$ rapidly increases when the polarizing voltage approaches the oxide flat band potential.

It is evident that even the anodic film grown on Ta-10at. $\% \mathrm{Nb}$ shows a behavior different from that shown by $\mathrm{Ta}_{2} \mathrm{O}_{5}$. In spite of the very close band gap value, the anodic film with the lowest $\mathrm{Nb}$ content shows a flat band potential more anodic than that of tantalum oxide, in agreement with the photoelectrochemical results. The shift toward the anodic direction of the flat band potential of all the mixed oxide with increasing $\mathrm{Nb}$ content, suggested by the photoelectrochemical results, is confirmed by the differential capacitance curves of Fig. 9.

In the high band bending region, i. e. for $\mathrm{e} \psi_{\mathrm{S}}>\left(\mathrm{E}_{\mathrm{g}} / 2-\Delta \mathrm{E}_{\mathrm{F}}\right)$, when a deep depletion region at the surface of a-SC/El junctions

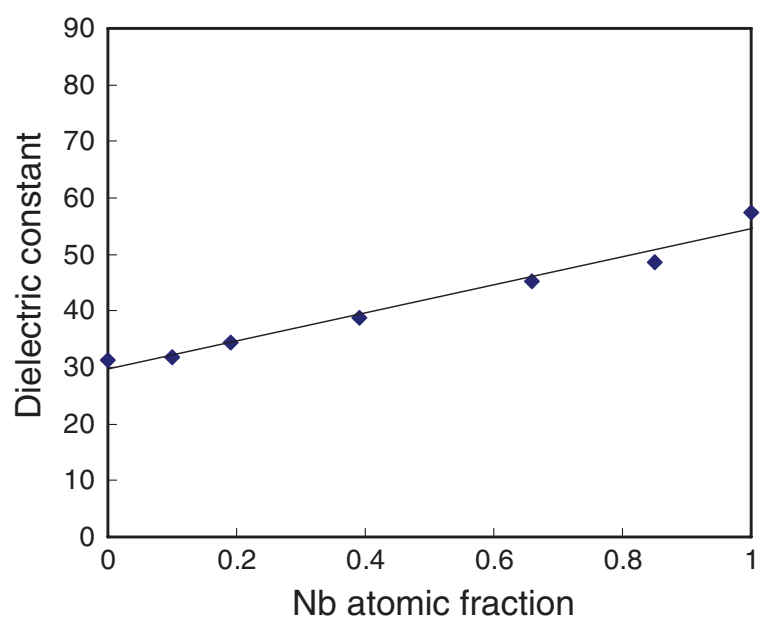

Figure 10. Dielectric constant $\varepsilon$ as a function of the $\mathrm{Nb}$ content into the oxide. 
appears $^{19}$ the total capacitance of barrier can be modelled as a two series capacitance:

$$
\frac{1}{C\left(\psi_{S}, \omega\right)}=\frac{1}{C\left(\psi_{g}, \omega\right)}+\frac{x_{g}}{\varepsilon \varepsilon_{0}}
$$

where the first term of eq. 11 represents the low band bending contribution calculated at the electrode potential where the Fermi level crosses
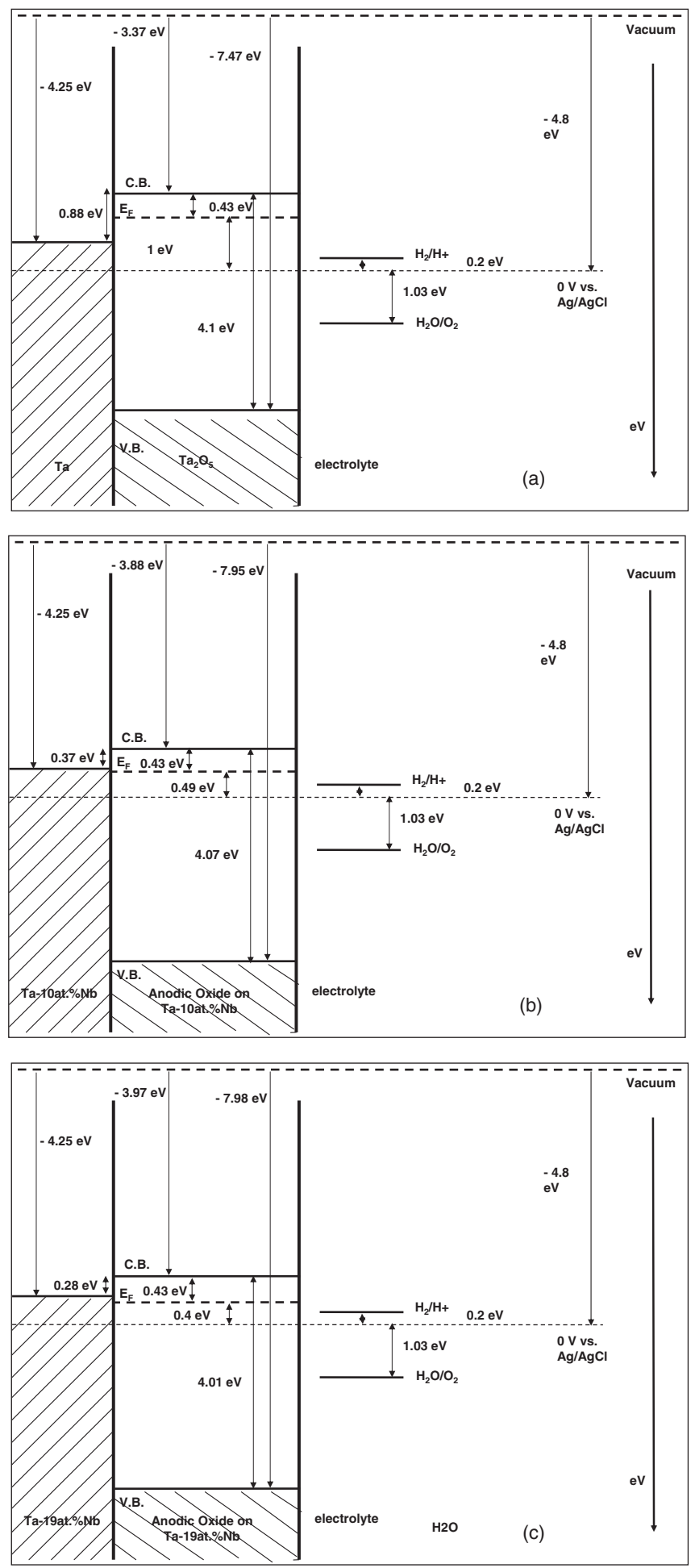

Figure 11. Sketch of the energetic levels of metal/oxide/electrolyte interface for anodic films grown on a) Ta, b) Ta-10at.\%Nb, c) Ta-19at.\%Nb. the mid gap energy and coincides with eq. 10 after notation substitution. The second term represents the capacitance of the deep depletion region going from the surface to the point $\mathrm{x}_{\mathrm{g}}$ of the junction, where a parabolic potential distribution exists, and is frequency independent. Under high band bending $\left(\mathrm{e} \psi_{\mathrm{S}}>\mathrm{E}_{\mathrm{g}} / 2-\Delta \mathrm{E}_{\mathrm{F}}\right)$ and high frequency $\left(\psi_{\mathrm{C}} \rightarrow 0\right), C\left(\psi_{S}, \omega\right) \cong C\left(\psi_{C}, 0\right)$ and, thus, we can assume that the space charge region width coincides with the whole oxide thickness. This allows to estimate the oxides' dielectric constant according to the following eq.:

$$
C=\frac{\varepsilon \varepsilon_{0}}{d}
$$

By subtracting to the measured capacitance the Helmholtz double layer contribution, assumed $\sim 20 \mu \mathrm{F} \mathrm{cm}^{-2}$ in concentrated aqueous solution (as $0.5 \mathrm{M} \mathrm{H}_{2} \mathrm{SO}_{4}$ is) ${ }^{20}$ we can have the idea on how the $\varepsilon / d$ ratio changes by changing the oxide composition. We know from the anodizing curves (see previous sections) as well as from the transmission microscopy images of ultramicrotomed sections ${ }^{8}$ that the film thickness increases with increasing $\mathrm{Nb}$ content into the mixed oxide. The knowledge of $d$ allows to estimate the oxide dielectric constant from the capacitance values measured at $5 \mathrm{kHz}$ at the highest band bending $\left(\mathrm{U}_{\mathrm{E}}=3 \mathrm{~V}\right)$, reported in Fig. 10 as a function of the film composition. $\varepsilon$ monotonically increases with increasing $\mathrm{Nb}$ content, as found for thicker films grown on the same investigated alloys. ${ }^{8}$ Such dependence also agrees with the dielectric constant calculated by computation method for $\mathrm{NbTaO}_{5}$, reported in ref. 16 .

Finally, we want to stress that eq. 9 allows to estimate $\Delta \mathrm{E}_{\mathrm{F}}$, provided that it is possible to estimate a frequency of the a.c. signal high enough to make the capacitance almost independent on the applied potential. The simultaneous knowledge of this energy distance and of the band gap value of the oxide allows to get the energetics of the metal/oxide/electrolyte interface, as reported in Fig. 11 for anodic films grown on Ta, Ta-10at. $\% \mathrm{Nb}$ and $\mathrm{Ta}-19 \mathrm{at} . \% \mathrm{Nb}$. A work function of $4.25 \mathrm{eV}$ has been assumed for tantalum and for the alloys, ${ }^{21}$ due to their low $\mathrm{Nb}$ content and by taking into account that a very close work function is reported for $\mathrm{Nb}(4.30 \mathrm{eV}$ according to ref. 21). These sketches provide an idea of the band offset for the investigated metal/oxide systems. With a $\mathrm{Nb}$ content of $19 \%$, we get a mixed oxide with a dielectric constant $10 \%$ higher than that of $\mathrm{Ta}_{2} \mathrm{O}_{5}$ with a reduction of less than $3 \%$ of the band gap. However, to have a complete set of information it is very important to have a look to the energetics of the metal/oxide interface, that shows a reduction of the band offset (see Fig. 11). If we consider that the metal or alloys to be anodized can be easily sputtered on a metal with a properly selected work function, we can hypothesize to control the band offset by properly selecting the materials involved in the fabrication of the metal/oxide interface.

\section{Conclusions}

$\mathrm{Ta}_{2} \mathrm{O}_{5}, \mathrm{Nb}_{2} \mathrm{O}_{5}$ and $\mathrm{Ta}-\mathrm{Nb}$ containing oxides grown by anodizing sputter-deposited $\mathrm{Ta}, \mathrm{Nb}$ and $\mathrm{Ta}-\mathrm{Nb}$ alloys of different composition were characterized by Photocurrent Spectroscopy and by impedance measurements.

Band gap values of $4.1 \mathrm{eV}$ and $3.4 \mathrm{eV}$ were estimated for anodic $\mathrm{Ta}_{2} \mathrm{O}_{5}$ and $\mathrm{Nb}_{2} \mathrm{O}_{5}$, respectively, while intermediate values were estimated for mixed oxides monotonically increasing by increasing the Ta content.

The estimated band gap values are in agreement with the proposed linear dependence of $\mathrm{E}_{\mathrm{g}}$ on the squared difference of electronegativity of the oxide constituents. This finding shows the potential of this correlation to predict the band gap value of an oxide knowing its composition.

Differential capacitance curves, recorded for all the investigated oxides in a wide range of electrode potential and for several frequencies of the alternative signal, were interpreted on the basis of amorphous semiconductor Schottky barrier, and allowed to determine the dielectric constant of the investigated oxides. According to the 
estimated values, $\varepsilon$ depends almost linearly on the atomic fraction of one of the partner cations into the mixed oxide.

The experimental results reported in this work suggest that by properly selecting the alloy composition it is possible tailoring both the oxides band gap and dielectric constant, which are key parameters in determining the performance of high-k materials.

\section{Acknowledgment}

MS and FDQ gratefully thank USAITC-A for providing the grant no. W911NF-09-10461.

\section{References}

1. K. Kukli, M. Ritala, and M. Leskela, J. Appl. Phys., 86, 5656 (1999).

2. Y. Matsui, M. Hiratani, I. Asano, and S. Kimura, Technical Digest - International Electron Device Meeting, p. 225 (2002).

3. Y. Matsui, M. Hiratani, S. Kimura, and I. Asano, J. Electrochem Soc., 152, F54 (2005).

4. K. Kishiro, N. Innoue, S. J. Chen, and M. Ypshimaru, J. Appl. Phys., 37, 1336 (1998).

5. J. C. Yu, B. C. Lai, and J. Y. M. Lee, IEET Trans. Electron Devices, 21, 537 (2000).

6. B. C. M. Lai, N. H. Kung, and Y. M. Lee, J. Appl. Phys., 85, 4087 (1999).

7. M. Stromme, G. A. Niklasson, M. Ritala, M. Leskela, and K. Kukli, J. Appl. Phys., 90, 4532 (2001).
8. S. Komiyama, E. Tsuji, Y. Aoki, H. Habazaki, M. Santamaria, F. Di Quarto, P. Skeldon, and G. E. Thompson, J. Soil. State Electrochemistry, in press.

9. F. Di Quarto, F. La Mantia, and M. Santamaria, in: Su-Il Pyun and Jong-Won Lee (Eds.), Modern Aspects of Electrochemistry, Springer, Inc., New York, 2009, pp. 231-316.

10. M. Pourbaix, Atlas of Electrochemical Equilibria in Aqueous Solutions, Pergamon Press, Oxford, 1966

11. N. F. Mott and E. A. Davis, Electronic Processes in Non-crystalline Materials, 2nd Ed., Clarendon Press, Oxford, 1979.

12. F. Di Quarto, S. Piazza, C. Sunseri, and M. C. Romano, J. Phys. Chem. B, 101, 2519 (1997).

13. F. Di Quarto, S. Piazza, M. Santamaria, and C. Sunseri, in: H. S. Nalwa (Ed.), Handbook of Thin Film Materials, Vol. 2, Academic Press, S. Diego, 2002, p.373.

14. F. Di Quarto, M. Santamaria, and C. Sunseri, Photoelectrochemical techniques in corrosion studies, in: P. Marcus, F. Mansfeld (Eds.), Analytical Methods in Corrosion Science and Technology, Taylor and Francis, Boca-Raton, 2006, p.697.

15. L. Pauling, "The Nature of Chemical Bond", Chap 3, Cornell University Press, Ithaca NY, 1960.

16. S. Clima, G. Pourtois, A. Hardy, S. Van Elshocht, M. K. Van Bael, S. De Gendt D. J. Wouters, M. Heyns, and J. A. Kitt, J. Electrochem. Soc., 157, G20 (2010).

17. F. Di Quarto, S. Piazza, R. D'Agostino, and C. Sunseri, J. Electroanal. Chem., 228, 119 (1987)

18. F. La Mantia, M. Santamaria, F. Di Quarto, and H. Habazaki, J. Electrochem. Soc., 157, C258 (2010)

19. F. Di Quarto, F. La Mantia, and M. Santamaria, Electrochimica Acta, 50, 5090 (2005).

20. H. Gerischer, Electrochim. Acta, 34, 1005 (1989).

21. Handbook of Chemistry and Physics, David R Lide Editor in Chief, $76^{\text {th }}$ Ed., 1995. 